\title{
CLONACIÓN, PRODUCCIÓN DE QUIMERAS Y CÉLULAS PLURIPOTENCIALES
}

\author{
CLONATION, PRODUCTION OF CHIMERAS AND PLURIPOTENCIAL CELLS
}

\author{
"Mariana Rojas; *Felipe Venegas; **Jean Luc Servey \& **Michel Guillomot
}

ROJAS, M.; VENEGAS, F.; SERVEY, J. L. \& GUILLOMOT, M. Clonación, producción de quimeras y células pluripotenciales. Int. J. Morphol., 22(4):343-350, 2004.

RESUMEN: La Biología del Desarrollo y la Biotecnología han avanzado enormemente en los últimos años. Los estudios que se están realizando actualmente con nuevas técnicas moleculares, nos conducen a una nueva era en el diagnóstico y en el tratamiento de muchas enfermedades congénitas. Actualmente, se ha logrado aplicar los conocimientos derivados de ella, con incipiente éxito, en los aspectos productivos y también en la terapia de distintas enfermedades del Hombre y de otros animales y, por último, existen importantes perspectivas en la protección de especies amenazadas. En este Review, se analizan algunos de los aspectos técnicos más interesantes de la clonación, producción de quimeras y obtención de células pluripotenciales, como también los objetivos y proyecciones en el campo veterinario y de la salud animal y humana.

PALABRAS CLAVE: 1. Clonación; 2. Quimeras; 3. Células pluripotenciales.

Los estudios que se están realizando actualmente y que utilizan nuevas técnicas moleculares y equipos de alta sofisticación, nos conducen a una nueva era en el diagnóstico y en el tratamiento de muchas enfermedades congénitas. Actualmente, se ha logrado aplicar los conocimientos derivados de ella, con incipiente éxito, en los aspectos productivos y también en la terapia de distintas enfermedades humanas y de otros animales y, por último, existen importantes perspectivas en la protección de especies amenazadas. A continuación, analizaremos algunos aspectos que han sido noticia permanente en los últimos años, como la clonación, la producción de quimeras, y la obtención de células madres (troncales).

Clonación: Las técnicas utilizadas para la clonación pueden ser de dos tipos: 1) la practicada por transferencia de núcleos, donde se generan individuos que son copias iguales al progenitor, como la oveja Dolly y 2) la técnica realizada por gemelación, partiendo de un óvulo fecundado (a la manera tradicional), se escinde, produciendo dos o más embriones. En este caso, la constitución genética de las crías es diferente a la de los padres, pero es exactamente igual entre ellas (Esponda, 2000).

Mamíferos clónicos creados por trasplante de un núcleo. Nos referiremos a la clonación en animales, en es- pecial a la oveja Dolly. Esta técnica de clonación con fines reproductivos no debería ser utilizada en el ser humano. Los derechos del Hombre a no ser programado genéticamente y a ser genéticamente único e irrepetible, constituyen una grave y seria objeción ética en contra de la clonación con fines reproductivos, por transferencia de núcleo de célula somática. En 1997, el grupo de Ian Wilmuth del Instituto Roslin de Edinburgo, logró un mamífero clónico mediante un trasplante de núcleo. (no hubo intervención del sexo masculino). Dolly es el primer caso de un mamífero clónico originado por una célula no sexual, y fue creada para obtener una réplica de una oveja transgénica que no se reproducía. Esto se realizó de la siguiente manera:

1) De una oveja de cabeza blanca se obtuvieron células de una glándula mamaria, que se mantuvieron en un medio de cultivo. De estas células se extrajeron los núcleos.

2) De ovejas de cabeza negra se obtuvieron óvulos, a los cuales mediante micromanipulación se les quitó el núcleo, quedando por lo tanto constituidos exclusivamente por su citoplasma y recubiertos por la zona pelúcida.

3) Los núcleos extraídos de las células mamarias (de una oveja de cabeza blanca) fueron inyectados en el interior del citoplasma de los óvulos (de una oveja de cabeza negra).

\footnotetext{
* Laboratorio de Embriología Comparada, Programa de Morfología, Facultad de Medicina, Universidad de Chile, Chile.

** Unité de Biologie du Développement et Biotechnologie, INRA, Francia.

Trabajo financiado por el Proyecto ECOS/ CONICYT B02 C03
} 
4) Los óvulos conteniendo el núcleo de la célula mamaria, se cultivaron por seis días, y aquellos que presentaron desarrollo embrionario (hasta estado de blastocisto) fueron transferidos al útero de ovejas de cabeza negra.

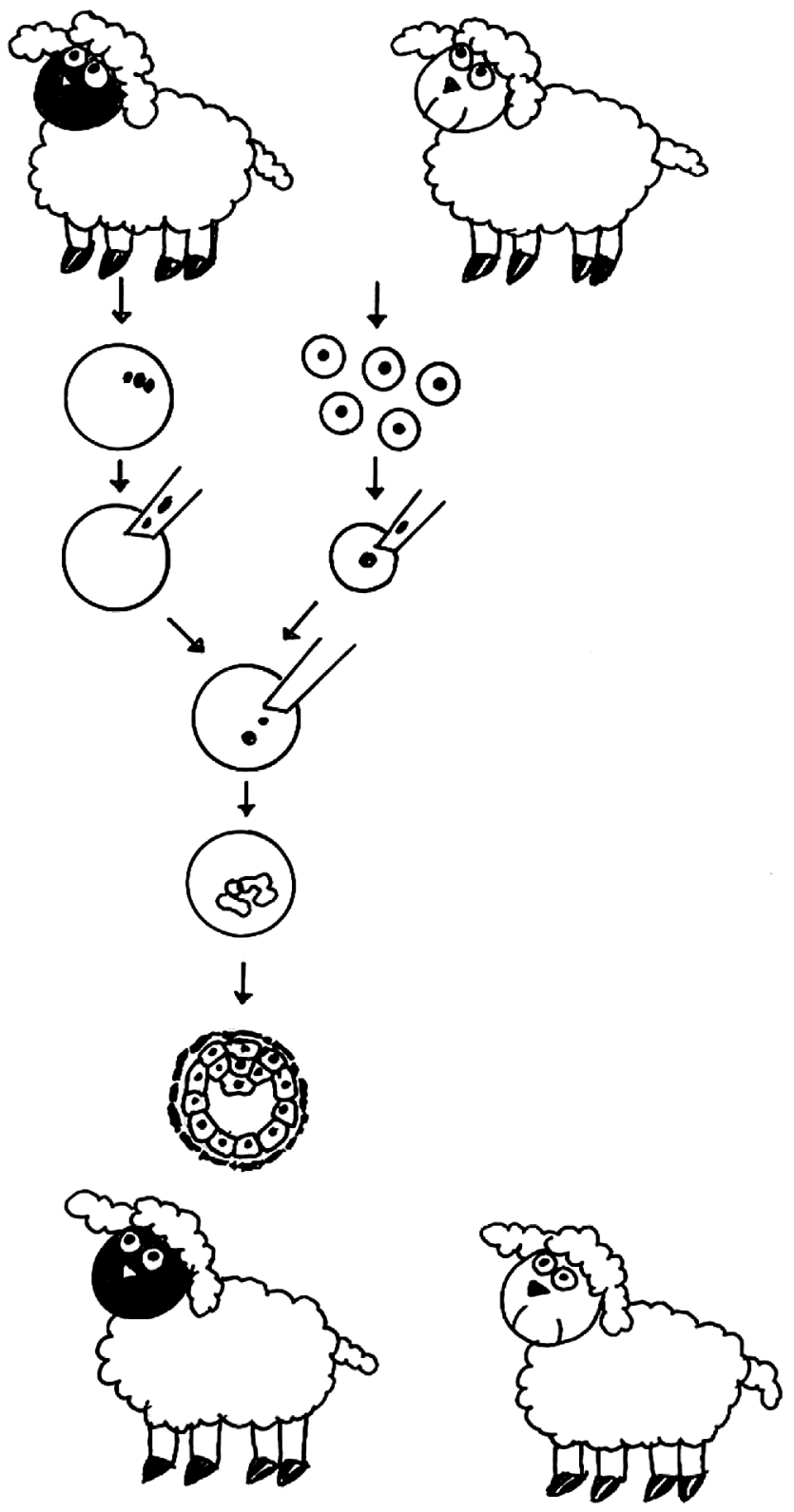

Fig. 1. De una oveja de cabeza negra (1) se obtiene un óvulo (2) al cual mediante micromanipulación se le extrae el núcleo (3). De una oveja de cabeza blanca (4) se extraen células de la glándula mamaria (5). De estas células se extraen los núcleos (6). Se inyecta un núcleo en el interior de un óvulo (7). Este óvulo con el núcleo inyectado (8) se transfiere al útero de una oveja de cabeza negra que hará las veces de madre de alquiler (9). Nace una oveja de cabeza blanca (10) que es geneticamente idéntica a la oveja que generó el núcleo (4).
Así nació Dolly, que posee sólo la información genética otorgada por el núcleo de la célula mamaria y cuyo sexo no podía ser sino femenino y el color de su cabeza fue blanco (Fig. 1).

Pedro Esponda, en su entretenido libro llamado "Seres del futuro" dice que se utilizaron 277 óvulos que fueron inyectados con núcleos. De ellos, 29 llegaron al estado embrionario de blastocisto y sólo nació una oveja que fue Dolly. Por lo tanto, el éxito del experimento fue extraordinariamente bajo $(0.3 \%)$.

En síntesis, se puede afirmar que son indispensables tres elementos: 1) un núcleo que contenga la información hereditaria completa, 2) el citoplasma de un óvulo que debe corresponder, en principio, a la misma especie que el núcleo trasplantado y 3) una madre receptora que anidará en su útero al embrión. Respecto al valor de la especie que anida el embrión, se debe notar que hay casos en que el útero de una especie puede anidar a un ejemplar de otra especie diferente, como el caso de una yegua que sirvió de madre huésped para una cebra, o el caso de ositos pandas que pueden desarrollarse en úteros de hembras de otras especies de osos.

Lo que parece irreemplazable es el citoplasma del óvulo, cuya composición es muy compleja en estructuras y moléculas, siendo capaz de organizarlo todo para que se produzcan las divisiones embrionarias. El citoplasma del óvulo muestra una capacidad inédita para transformar la expresión génica de un núcleo ya programado por la naturaleza (como el de células ya diferenciadas como la glándula mamaria). Es tal el papel de este citoplasma ovular, que es capaz de hacer que estos núcleos trasplantados puedan desdiferenciarse, reprogramarse y emprender la embriogé-nesis. Probablemente, el citoplasma del óvulo posee moléculas que toman parte en este mecanismo, pero en este momento no sabemos exactamente de qué moléculas se trata. El grupo francés dirigido por Xavier Vignon trabaja en dilucidar cuáles son los mecanismos moleculares que permiten el retorno de un núcleo de célula ya diferenciada, a un núcleo que es totipotente.

La clonación ofrece importantes oportunidades para la preservación genómica de animales en riesgo de extinción, pero su eficiencia es reducida. Se ha considerado que uno de los factores relacionado con esta baja eficiencia es el origen de las células donadoras de núcleos. Debido a esto, en nuestro grupo hemos realizado un estudio inmunohistoquímico de células obtenidas de biopsias de piel de bovinos adultos y neonatos, después de ser cultivadas "in vitro" por períodos de una a tres semanas. 
Las biopsias de cuatro pabellones auriculares de bovinos (tres hembras adultas y un neonato), fueron desinfectadas y seccionadas en cortes finos, incubadas en medio Eagle Dulbecco modificado, a $37^{\circ} \mathrm{C}$. Incubadas con acutasa, por tres minutos, lavadas con PBS, inmersas en BFS y antibióticos, centrifugadas dos veces a $1000 \mathrm{rpm}$ por 5 minutos. El precipitado de fibroblastos fue depositado en una placa Petri con medio de cultivo. Posteriormente, las células fueron caracterizadas inmunohistoquímicamente mediante an- ticuerpo anti-citokeratina 8-18 y anti vimentina en los sucesivos pasajes.

Inicialmente las células fueron vimentina positivas (Fig. 3) y algunas citokeratina positivas (Fig. 4). Entre los pasajes 6 a 10, todas las células fueron vimentina positivas, demostrando que eran sólo fibroblastos. No encontramos diferencias significativas entre los cultivos de células de adultos y neonatos.
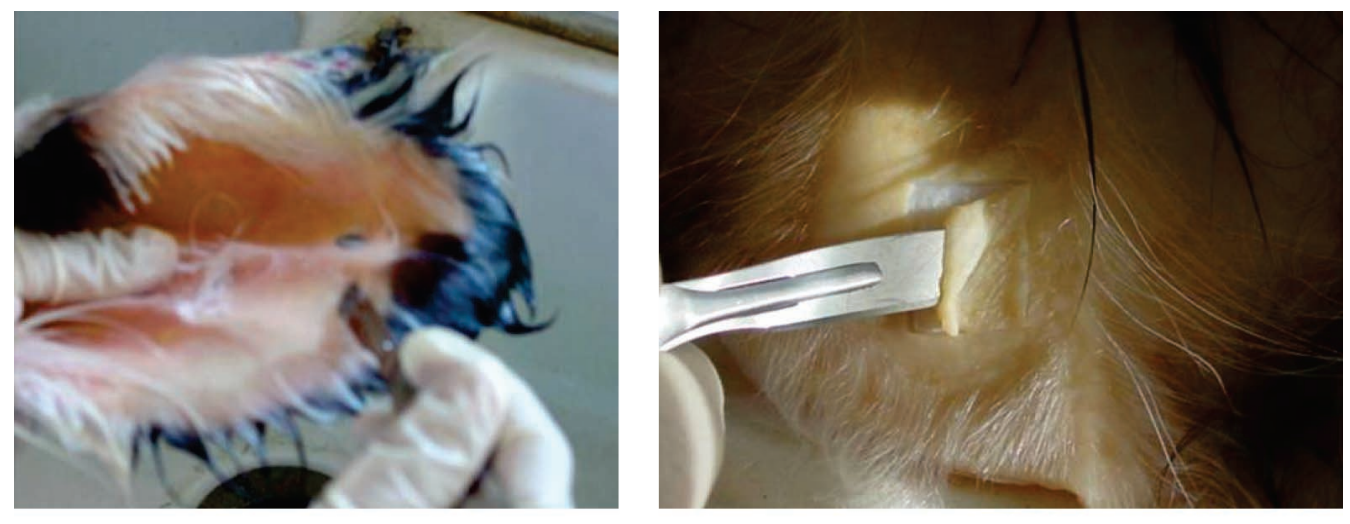

Fig. 2a y b obtención de biopsia de la dermis del pabellón auricular de una vaca (Bos taurus). c y d
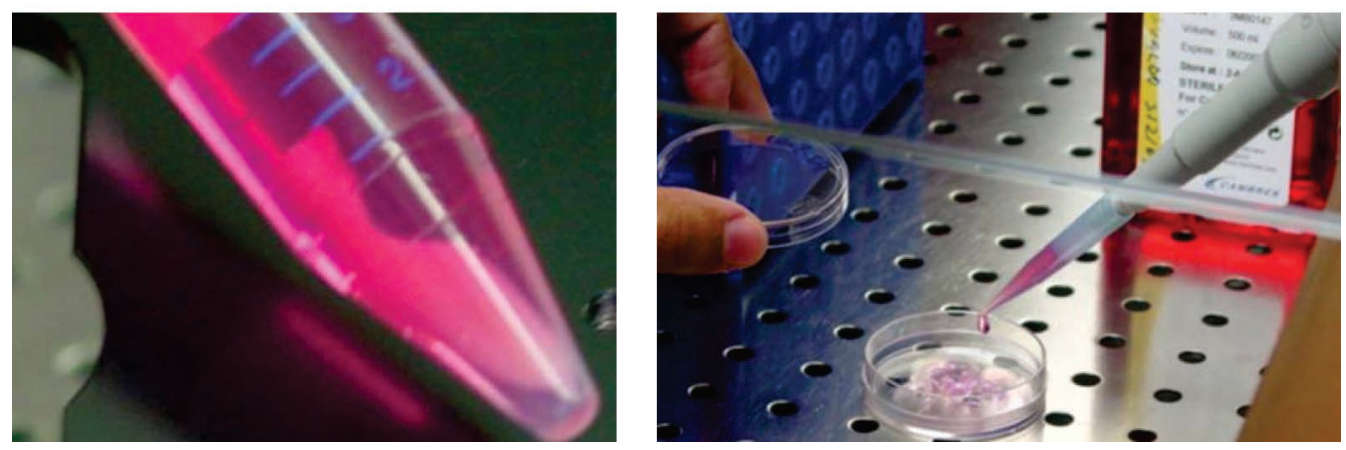
incubación en medio de cultivo.

Producción de quimeras. Una quimera es un animal que tiene características de dos o más especies. La quimera se origina por la mezcla de células provenientes de especies diferentes y posee las características de los dos individuos que genéticamente lo originan. Cuando hablamos de quimeras, nos referimos a las logradas por métodos experimentales de manipulación embrionaria y pueden ser de diferentes especies o de una misma especie.

Para algunos autores hay dos tipos de quimeras. 1) Primarias: aquellas naturales o artificiales que desde los estadios embrionarios presentan dos poblaciones celulares genéticamente diferentes. 2) Secundarias: en las que los tejidos u órganos de dos fetos o adultos diferentes se combinan. El mejor ejemplo de estas quimeras secundarias es el caso de los trasplantes de órganos, en los que un órgano de la misma o de otra especie es introducido y se incorpora en el cuerpo de un animal.
Las primeras quimeras fueron desarrolladas en 1920 , en el laboratorio de Hans Spemann por fusión de embriones tempranos de anfibios, pero los primeros experimentos que desarrollaron quimeras en mamíferos, se realizaron en la década de los años 60 y fueron logrados por Beatrice Mintz, empleando métodos de micromanipulación de embriones.

Beatrice Mintz utilizó mórulas provenientes de cruzamientos de parejas de conejos albinos y también mórulas de parejas de conejos negros. Las mórulas fueron separadas de la zona pelúcida mediante tripsina, y luego fueron fusionadas. El blastocisto gigante resultante se colocó en el útero de una madre receptora, que había sido hormonalmente tratada para simular una gestación. El resultado fueron crías con cuatro padres (tetraparentales), que presentan una cubierta de pelos formada por manchones de pelo blanco y manchones de pelo negro (Fig. 5). 


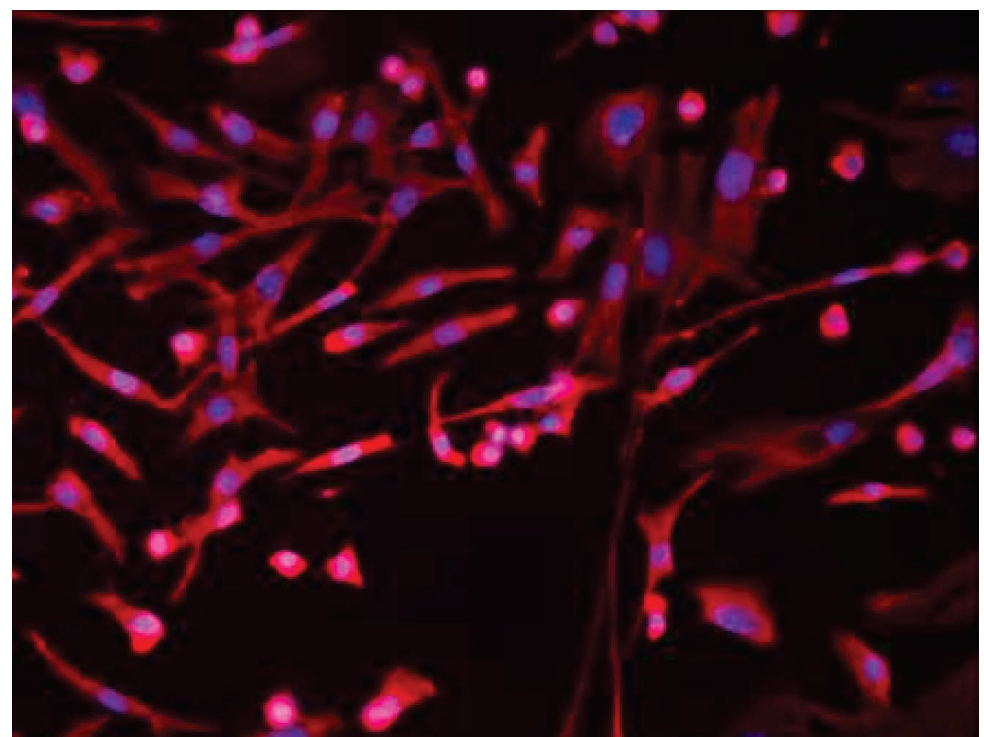

Fig. 3. Cultivos de fibroblastos marcados con técnicas de inmunofluorescencia de doble marcaje: Los núcleos se observan con Hoechst y los filamentos intermedios con un anticuerpo antivimentina.

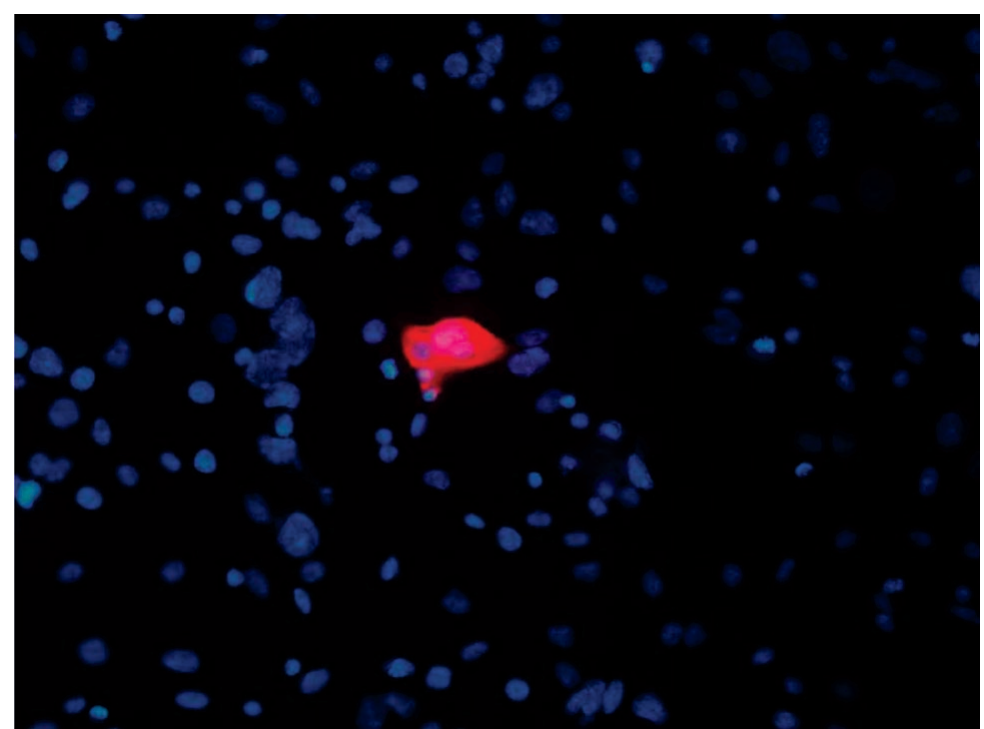

Fig. 4. Técnica de Inmunofluorescencia que permite el doble marcaje para los núcleos de todas las células (azul) y filamentos intermedios de células epiteliales. (anticuerpo anticitokeratina) /rojo)

Más tarde, se produjeron de la misma forma quimeras en conejos y ovejas. Este método se emplea habitualmente cuando se fabrican los animales knock-out, los cuales pueden ser considerados también como quimeras.

Pero no cabe duda de que dentro de las quimeras de mamíferos, el caso mas interesante ha sido el de la ovejacabra creada en Cambridge (Inglaterra) por Fehilly y Willadsen. Estos investigadores utilizaron blastocistos de cabra y oveja. El embrioblasto de cabra fue introducido dentro del blastocisto de una oveja. El embrión así forma- do fue transferido a una oveja receptora. El animal que nació mostró una mezcla de ambas especies: lo más destacado fue su pelaje que presentaba las características de ambas especies: y sus cuernos que tenían la forma de los de la cabra, pero que aparecían enroscados como los de oveja. Asimismo, su sangre contenía células de ambas especies. Existían en este animal otras características interesantes, como que se parecía fisicamente más a una cabra, aunque prefería la compañía de las ovejas. También el análisis de sus proteínas mostró que poseía características de ambas especies, pero que predominaban las de oveja. Respecto a su comportamiento reproductivo, demostró ser fértil aunque era capaz sólo de copular con ovejas. Este experimento es realmente único y mostró la posibilidad experimental de obtener una quimera, tal como las descritas en la mitología. (Fig. 6)

Los estudios realizados con quimeras son de gran interés para analizar el proceso embriológico, ya que se pueden fabricar quimeras utilizando embriones de diferentes edades. Por ejemplo, cuando se mezcla un embrión de cuatro células con uno de ocho, esta última forma el embrión, mientras el de cuatro células forma el trofoblasto. Al respecto, se debe notar que el trofoblasto es el que interactúa con el útero materno, por lo tanto, esta técnica podría ser usada potencialmente para producir transferencias embrionarias entre especies diferentes.

Los embriones de una especie dada, que han sido obtenidos por clonación, no se pueden implantar en el útero de una hembra receptora de especie diferente. En relación con la implantación, sólo el trofoblasto (extraembrionario) está implicado en las interacciones con los tejidos maternos. La obtención de conceptus quiméricos constituídos por el trofoblasto del blastocisto bovino (compatibles con el receptor) y de tejidos embrionarios de una especie de interés filogenéticamente cercana, podría relacionarse con el éxito de la clonación de animales de interés genético y en peligro de extinción.

En el estudio esperamos trasplantar embrioblastos de una especie de ciervo, en el interior de vesículas trofoblásticas de otra especie de ciervos, después de la ablación del embrioblasto. Los embriones quimeras así reconstituidos, serán analizados después de ser cultivados in vitro. 

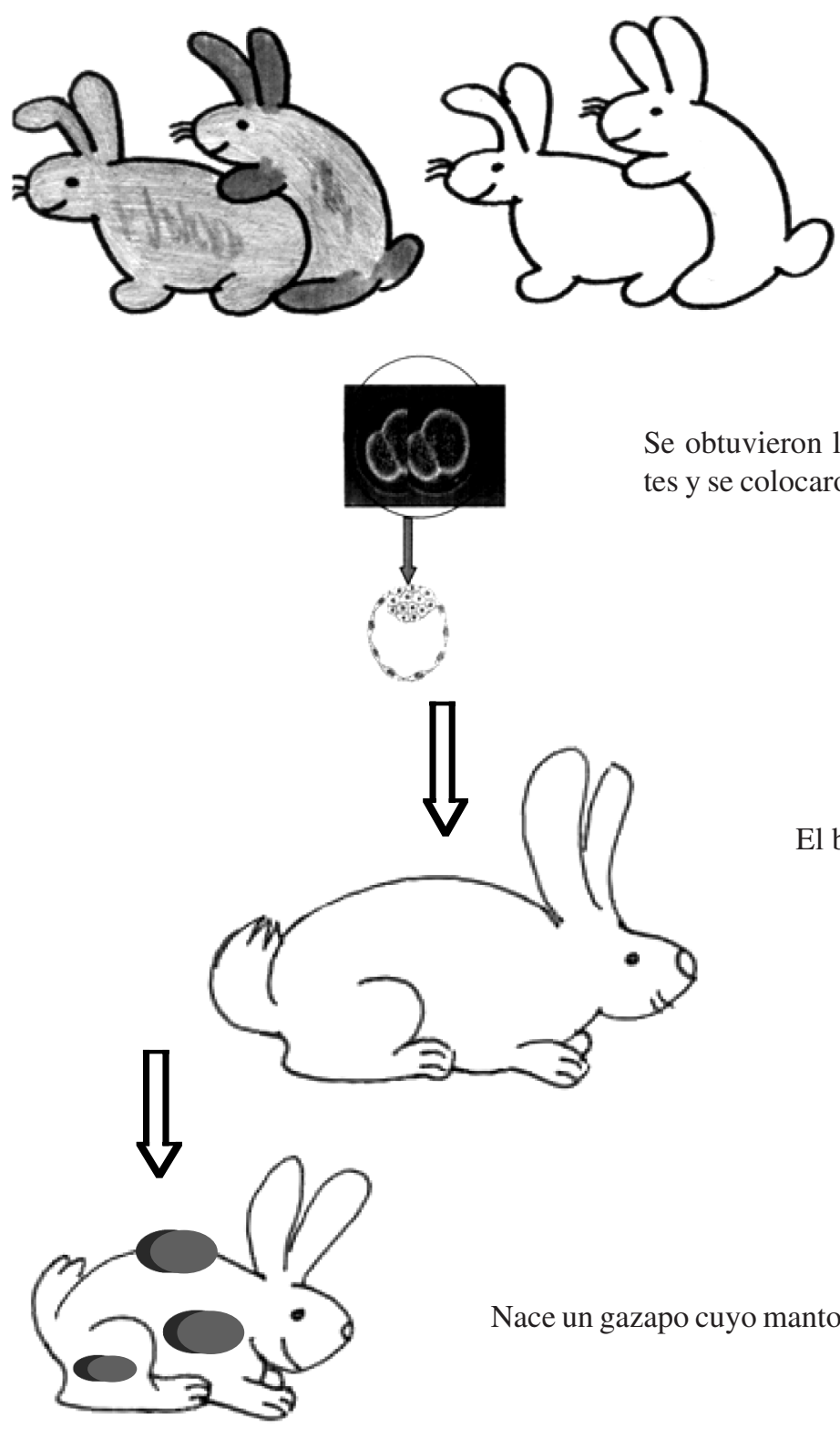

Nace un gazapo cuyo manto presenta manchones negros y blancos.
Se obtuvieron las mórulas resultantes y se colocaron en una placa Petri.
Se cruzaron parejas de conejos de pelaje negro y también conejos de manto blanco.
El blastocisto se transfiere a una coneja receptora.
Las células madres pluripotenciales: Actualmente, son muchos los laboratorios en todo el mundo que trabajan para obtener células pluripotenciales embrionarias. Estas células son llamadas así porque tienen la potencialidad de originar todos los tipos celulares que existen en el cuerpo y se han convertido en una esperanza terapéutica para muchas enfermedades tanto del Hombre como de los animales.

Las células madres embrionarias son las únicas capaces de autorrenovarse y diferenciarse en muchas líneas celulares. Algunos tejidos adultos de mamíferos conservan también células madres, pero éstas son capaces de generar sólo un número limitado de tipos celulares.
Las células madres obtenidas de embriones en la etapa de blastocisto tienen la capacidad de formar todas las células del cuerpo, porque mantienen el cariotipo normal, y una alta actividad telomerasa, además, logran en cultivo, un notable potencial de proliferación durante un largo período de tiempo, dando la posibilidad de una expansión ilimitada.

Las células madres se obtienen del embrioblasto de un blastocisto y deben cultivarse "in vitro" para obtener líneas de células pluripotenciales. Estas células madre pueden seguir los siguientes dos caminos, dependiendo del medio de cultivo que se utilice: a) mantenerse en un estado 


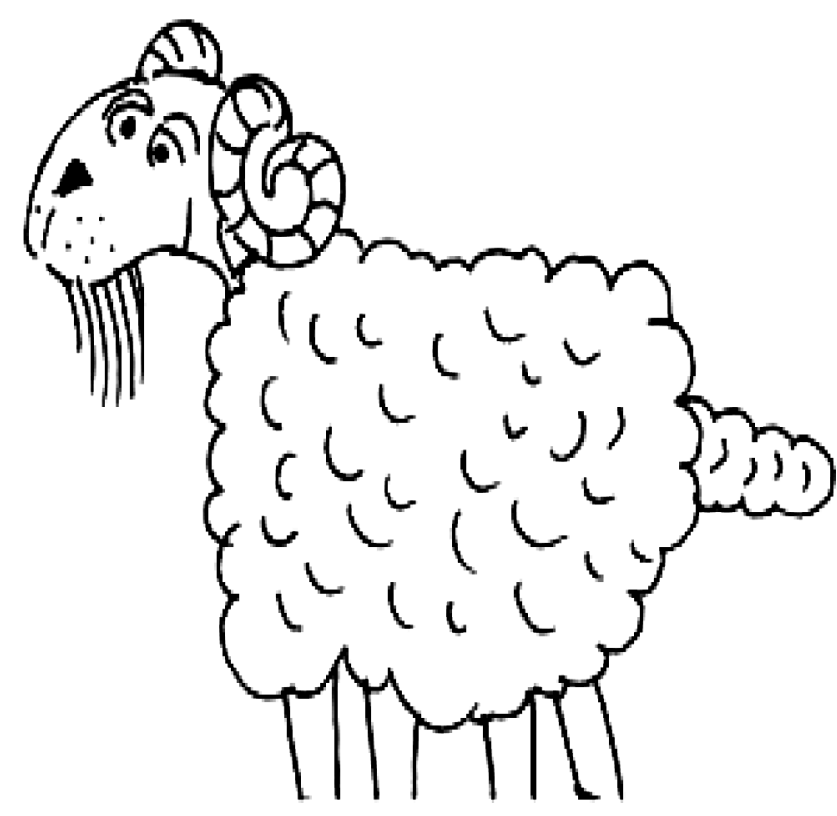

Fig. 6. Quimera: oveja-cabra

indiferenciado y b) diferenciarse en líneas celulares más específicas, por ejemplo cardíacas, neurales, sanguíneas, etc.

Debido a que estas células pueden proliferan indefinidamente en un medio de cultivo y luego diferenciarse en múltiples tipos celulares, las células humanas potencialmente pueden proveer de un aporte ilimitado de tejidos para trasplantes humanos. La terapia de trasplante basado en estas células, es una promesa de tratamiento exitoso para una variedad de enfermedades como Parkinson, diabetes, alteraciones cardíacas, alteraciones degenerativas del cerebro o lesiones de la médula espinal, y también para producir nuevas células sanguíneas en personas con anemia. Sin embargo, aún hay barreras que superar para un exitoso tratamiento clínico.

Prácticamente toda la investigación relacionada con células madres embrionarias se ha desarrollado en el ratón de laboratorio y algunos otros animales como conejos, ovejas y vacas. En la especie humana esta investigación está mucho menos desarrollada debido a los aspectos éticos y legales. En Chile, prácticamente no se desarrolla investigación experimental en células humanas, pero sí en animales, En nuestro laboratorio hemos observado que, a partir de células germinales primordiales embrionarias de conejo, se pueden también generar células pluripotenciales y teratomas (Montiel et al., 2001; Rojas et al., 2001; Rojas et al., 2004).

Aún cuando la mayoría de los estudios se han reali- zado en animales, en 1988, dos laboratorios informaron que habían obtenido células madres de embriones humanos. En estos casos, las células madres fueron obtenidas a partir de células germinales primordiales derivadas de fetos abortados espontáneamente. En ambos casos las células embrionarias fueron pluripotentes, y capaces de proliferar y diferenciarse en el cultivo y también de formar otras células madres que producían neuronas y sangre (Geahart, 1998; Thomson et al., 1998)

Esta terapia fue probada primero en el ratón, donde las células madres fueron sembradas en una placa de cultivo, la cuál tenía un medio líquido con acido retinoico, se obtuvieron así células madres de la estirpe neuroniana, las cuales al ser trasplantadas en el ratón generaron neuronas funcionales (McDonald et al., 1999).

Cuando las mismas células madres eran depositadas sobre un piso de celulas nutricias fibroblásticas y un medio liquido que, en vez de ácido retinoico, contiene factor de crecimiento fibroblástico y factor de crecimiento derivado de plaquetas se obtuvieron, células madres gliales, y cuando ellas se trasplantaron en ratones que tienen una deficiencia genética de la función glial se obtuvieron células gliales funcionales y el defecto fue eliminado, por lo que los ratones mejoraron (Fig. 3). Las células gliales o neuroglía son las otras células del sistema nervioso y colaboran con las neuronas proporcionándoles: sostén, y nutrición. (Brüstle et al., 1999)

El gran problema que impide extrapolar estas técnicas a la especie humana es que los ratones de laboratorio utilizados eran consanguíneos, y los seres humanos no lo son, por lo tanto existe un problema de rechazo inmunológico que no se ha podido superar con seguridad, las células madre deberían ser modificadas, o bien de acuerdo a otros autores se debería clonar un embrión temprano a partir de las células somáticas del paciente y así generar sus propias células madre. (Gilbert, 2000).

El laboratorio Advanced Cell Technology ha estado dedicado a la clonación de un embrión humano, el objetivo no es obtener un ser humano sino la obtención de células madres. La obtención de células troncales obtenidas de embriones generados por transferencia de núcleos, y no por vía reproductiva, plantea también un problema ético. El debate sobre esto, así como la consideración del momento en que comienza una vida en estos casos, de reproducción tan distinta a lo habitual no se ha terminado. Si bién es cierto, la vida comienza en el momento de la fecundación, es claro que en este caso no hay fecundación, ni tampoco hay dos gametos que se encuentren, ni la información genética de dos sexos que se combinan. 


\section{Células madres que no provienen de embriones tempranos.}

1.- Las células de la médula ósea son progenitoras de tejidos, tales como cartílago, hueso, células hematopoyéticas y adiposas. Actualmente, se realizan trasplantes locales de las células de la médula ósea, las cuales permiten la eficiente reconstrucción de defectos óseos y se podrán utilizar en un futuro próximo para solucionar problemas ortopédicos.

2.- Otra fuente de células madres es la sangre que fluye por el cordón umbilical. En $1 \mathrm{ml}$ de sangre del cordón umbilical, hay aproximadamente 8000 progenitores de eritrocitos, entre 13 y 24 mil progenitores mieloides, y entre 1000 y 10.000 células madres pluripotenciales. Esta forma de obtención de células madres estaría mucho más de acuerdo con diversas regulaciones éticas. En los últimos años se han utilizado células madres provenientes de sangre del cordón umbilical, para trasplantes, en lugar de células de la médula ósea. Más de 500 de estos trasplantes han sido realizados en todo el mundo, principalmente en niños con enfermedades sanguíneas incluidas las leucemias linfoide y mieloide, diversos tipos de anemia, con muy buenos resultados. Actualmente, se están formando varios bancos de células provenientes de cordones umbilicales y muchos padres están considerando congelar un segmento de cordón umbilical de sus hijos y mantener allí esas células hasta el momento en que ellos pudieran necesitar algún trasplante de éstas. Existen también otras células madres pero que no son pluripotentes, sino que son monopotentes, por ejemplo las células de la capa basal de la piel, que sólo originaran piel.

Para concluir, señalamos que son las células embrionarias del blastocisto, las que tienen capacidad de generar todas las células del organismo, las otras células madres, como las del cordón umbilical y la médula ósea del adulto, tienen un potencial más restringido.

Probablemente, ninguna de estas técnicas resulte convincente para ser utilizadas en la especie humana, sin embargo, parece ser que los estudios iniciados, con relación a la búsqueda y obtención de células madres, no se detendrán, De acuerdo, a lo escrito por Daniel Perry en la revista Stem cell, la voz de los pacientes se ha convertido en un sonido muy poderoso en el debate de las células madres, existiendo millones de pacientes afectados por enfermedades, quienes pueden ser ayudados por estas investigaciones en células pluripotenciales.

$\mathrm{Al}$ parecer, las investigaciones sobre estos temas recién comienzan.

ROJAS, M.; VENEGAS, F.; SERVEY, J. L. \& GUILLOMOT, M. Clonation, chimeras and production pluripotential cells. Int. J. Morphol., 22(4):343-350, 2004.

SUMMARY: Developmental Biology and Biotechnology had advanced a lot in the last years. Using new molecular techniques, the analysis opens a new age in diagnostic and treatment of a number of congenital diseases. At present, some of this knowledge has been successfully applied to the therapy of some human and animal pathologies, and there are also promising perspectives for protection of endangered species. In this review, some of the more interesting aspects of clonation, chimerism, and the production of pluripotential cells as well as the objectives and projections on veterinary and animal health are dealt with.

KEY WORDS: 1. Clonation; 2. Chimeras; 3. Pluripotential cells.

\section{REFERENCIAS}

Brüstle, O. et al. Embryonic stem cell-derived glial precursors: A source of myelinating transplant. Science, 285:754-6, 1999.

Esponda, P. Seres del futuro "De la fecundación in vitro a los clónicos y transgénicos” Mundo Vivo, 2000.

Dowsing, A.T.; Gougoulidis, T.; Dowsing, B. J.; Draber, P. \& Trounson, A. O. The Stage-Specific Expression of TEC-1, -2, -3, and -4 Antigens on Bovine preimplantation embryos. Mol. Rep. Dev., 49:19-28, 1998.
Geahart, J. New potential for human embryonic stem cells. Science, 282:1061-2, 1998.

Gilbert, S. Development Biology, Sinauer Associates. Sunderland, Massachusetts. 2000.

Mc Donald, et al. Transplanted embryonic stem cells survive, differentiate, and promote recovery in injured rat spinal cord. Nature Med., 5:1410-2, 1999.

Montiel, E.; Guillomot, M.; Rojas, M.; Bustos-Obregón, 
E. \& Flechon, J. Primordial germ cell characterization by immunohistochemistry of vasa-homologue protein in preimplantational rabbit embryos. Int J. Dev. Biol., 48: 141-2, 2001.

Rojas, M. A.; Vignon, X.; Montenegro, M. A.; del Sol, M.; BustosObregón, E. \& Fléchon, J. Caracterización aislamiento y cultivo de células germinales primordiales de conejo. Rev. Chil. Anat. 19(2):213-20, 2001.

Rojas, M. A.; Guillomot, M.; Montiel, E.; Venegas, F. \& Bustos-Obregón, E. Marcadores específicos para el reconocimiento de celulas germinales primordiales en las distintas etapas de su evolución. XIII Congreso de Veterinaria, Valdivia, 2004.

Thomson, J. A. et al. Embryonic stem cells line derived from human blastocyst. Science 282:1145-7, 1998.
Dirección para correspondencia:

Prof. Dra. Mariana Rojas

Facultad de Medicina

Universidad de Chile

Santiago

Fono-Fax: 56-2-2225710

Email:mrojas@med.uchile.cl

Recibido : 22-08-2004

Aceptado: 15-11-2004 